\title{
ESTIMATES OF PHYLOGENY AND BIOCHRONOLOGY
}

\author{
EMMANUEL FARA \\ UMR 6046 du CNRS, Laboratoire de Géobiologie, Biochronologie, et Paléontologie Humaine, Université de Poitiers, 40 avenue du \\ Recteur Pineau, 86022 Poitiers cedex, France. efara@univ-poitiers.fr \\ MAX C. LANGER \\ Departamento de Biologia, FFCLRP, USP, Av. Bandeirantes 3900, 14040-901, Ribeirão Preto, SP, Brazil.mclanger@ffclrp.usp.br
}

\begin{abstract}
Without the help of stratigraphic data, most quantitative biostratigraphic methods would fail to ordinate assemblages that have no or very few co-occurring taxa. In such instances, the hierarchical pattern of cladograms may provide an independent means to ordinate fossil assemblages. Here we propose a method that uses phylogenetic information for the inference of biochronological ordination. The faunal components of various fossil assemblages are scored according to their placement in the cladograms of the groups to which they belong. The faunal ordinations inferred from each of the clades are then cross-compared. If these ordinations are statistically congruent, their scores are averaged into a single final order. The major advantage of the method is that it can ordinate fossil assemblages that share no taxa. The erection of such a 'phylogenetic biochronology' relies on explicit assumptions of phylogenetic accuracy, character acquisition, and completeness of the fossil record. This exploratory algorithm yields better results when good phylogenetic hypotheses are known and when the samples are not temporally clustered. A generalised mismatch between stratigraphic and phylogenetic data or poorly-known phylogenetic relationships may severely affect the outcomes of the method. Phylogeny estimates provide additional, independent but non-exclusive information for biochronologic inferences. Comparison of phylogenetic biochronologies with other sources of evidence provides a heuristic basis to address various aspects of paleoecology, paleobiogeography, quality of the fossil record and phylogenetic hypotheses.
\end{abstract}

Key words: Biochronology, phylogeny, cladogram, ordination, phylogenetic biochronology

RESUMO - Sem informações de cunho estratigráfico, a maioria dos métodos bioestratigráficos quantitativos são incapazes de ordenar assembléias fossilíferas que compartilhem poucos ou nenhum táxon. Nestes casos, o padrão hierárquico inferido a partir dos cladogramas pode representar uma ferramenta independente neste processo. É apesentado aqui um método que utiliza a informação filogenética no estabelecimento de ordenamentos biocronológicos. Neste método, cada componente das assembléias fossilíferas estudadas é quantificado de acordo com sua posição em um cladograma representativo da linhagem biológica a que pertence. Posteriormente, os ordenamentos faunísticos definidos com base no cladograma de cada linhagem são comparados. Caso mostrem-se estatisticamente congruentes, estes serão integrados em uma ordem final única. A principal vantagem deste método é que ele pode ordenar assembléias fossilíferas que não compartilham táxons, sendo útil para o estudo de certos segmentos da história geológica da vida. A construção de uma 'biocronologia filogenética' tem como base pressupostos explícitos de exatidão filogenética, aquisição de caracteres e completitude do registro fóssil. $\mathrm{O}$ algoritmo proposto leva à resultados melhores quando filogenias robustas são conhecidas. Por outro lado, se estas são instáveis, os resultados do método podem ser severamente afetados. Filogenias fornecem dados adicionais, independentes e não-excludentes para inferências biocronológicas. Além do mais, o cruzamento de dados filogenéticos, paleoecológicos e paleobiogeográficos com aqueles provenientes de biocronologias filogenéticas pode gerar um embasamento heurístico para a discussão de temas relevantes nestas áreas do conhecimento, bem como para o estudo da qualidade do registro fossilífero.

Palavras-chave: Biocronologia, filogenia, cladograma, ordenação, biocronologia filogenética

\section{INTRODUCTION}

Since the early nineteenth century, sedimentary deposits have been correlated on the similarity of their fossil content. The main principles of biostratigraphy were therefore established long before the acceptance of the theory of evolution. The latter provided an explanation for the observed faunal successions, but it did not affect the way strata were correlated (e.g. Rudwick, 1976). Besides, taxonomy has been of central importance in recognising faunal components throughout the history of biostratigraphy (Hedberg, 1976; Pearson, 1998a). Taxonomic procedures have themselves been strongly influenced by evolutionary concepts, with the genealogical relationships of organisms as the major basis 
for evolutionary systematics (Simpson, 1944, 1953). This premise is also essential in the cladistic approach to taxonomy (Hennig, 1966).

Nevertheless, most biostratigraphic methods do not directly use the information provided by the phylogenetic relationships of taxa. Traditional biostratigraphic studies, for example, correlate fossil assemblages according to their taxonomic similarity. This approach relies on presence/ absence data of either the entire fauna (e.g. Hooker, 1996) or of particular taxa (e.g. Lucas \& Hunt, 1993; Heckert \& Lucas, 1998, 2002) but it is considerably weakened when sampling regimes are poorly known (Alroy, 1992). Other quantitative methods have been designed to overcome this problem. This includes the "Unitary Associations" method of Guex (1977, 1987, 1991), as well as the "Appearance Event Ordination" method introduced by Alroy (1994). Both methods minimise the overlap of taxonomic distributions ("conjunction" of Alroy, 1992, 1994) and can produce hypothetical age-range charts, but they differ in several aspects (see Alroy 1994 for a discussion). This methodological arsenal complements other non-phylogenetic ordination methods, such as the application of seriation to biochronological problems (Burroughs \& Brower, 1982). The important point is that all these methods will be of little use when most taxa are known from only a single occurrence.

Until now, the use of phylogenies for biostratigraphic purposes has relied mainly on subjective statements about the "stage of evolution" of faunas. Notable exceptions are the character-based approach proposed by Gerrienne \& Streel (1994) and the "cladochronogram analysis" of Martinez (1995).
The former method uses derived morphological character states to ordinate fossil assemblages, whereas the latter is a cladistic-derived biochronological method that applies a parsimony criterion to a taxon/lineage matrix. In this matrix, evolutionary stages within a lineage are coded as character states. The result is a "cladochronogram" of assemblages in which the internodes represent the temporal axis. The presence of a same derived species in several assemblages is considered as an equivalent to a synapomorphy in cladistic analysis.

Importantly, these two phylogeny-based approaches do not introduce temporal data into phylogenetic analysis per $s e$, and they are therefore opposite to stratocladistic and stratophenetic methods (Fisher, 1992, 1994; Gingerich, 1979). The same applies to the method introduced here and that attempts to use the hierarchical pattern of cladograms to hypothesize the relative chronological positions of fossil assemblages.

\section{CONCEPT}

The intuitive appeal of using phylogenetic estimates to ordinate fossil assemblages on a temporal axis can be presented as follows: Figure 1 shows a simple case in which representatives of only two clades $(\alpha$ and $\beta$ ) are found in two fossil assemblages. The two latter could be correlated because they share a taxon (gray square) that belongs to clade $\alpha$. Similarly, "basal" (open circle) and "derived" (black circle) taxa of clade $\beta$ occur in Assemblages 1 and 2. Note that the terms "basal" and "derived" refer here to taxa that

\section{Assemblage 1: $\square \bigcirc$}

Assemblage 2:

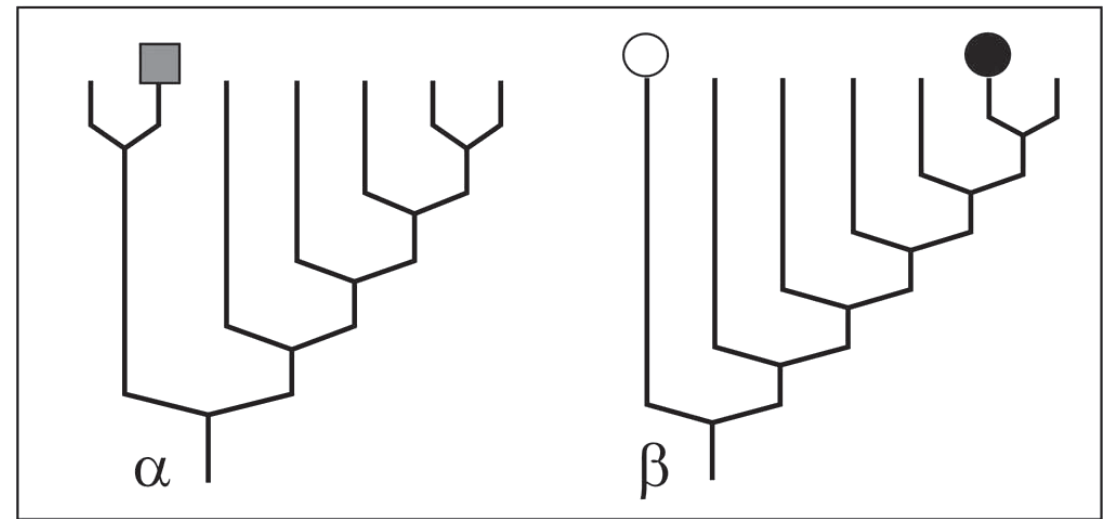

Figure 1. Representatives of two clades $\alpha$ and $\beta$ are found in two fossil assemblages (Assemblage 1 and 2). A correlation of the two assemblages can be proposed according to their faunal similarity (they have the 'square' taxon from clade $\alpha$ in common). Alternatively, the faunal components belonging to clade $\beta$ could be used to ordinate the two assemblages. Under some theoretical assumptions (see text), Assemblage 2 may be suggested to be younger than Assemblage 1 because it contains a more derived representative of clade $\beta$ than does Assemblage 1. 
have respectively low and high patristic distance from the base of the tree. Under the assumptions discussed below, we expect more derived taxa to arise after less derived taxa, so that their occurrence may be used to assess the minimal relative age of fossil assemblages. Following this line of reasoning, Assemblage 2 seems younger that Assemblage 1 because it contains a more derived taxon of clade $\beta$. The proposal of a quantitative method using this rationale to ordinate fossil assemblages represents the main part of this paper, but the theoretical requirements for its application must be reviewed first.

\section{THEORETICAL PREMISES}

Although the empirical correlation between the order of inferred cladogenetic events and the sequence of first occurrences of taxa in the fossil record has been intensely studied in recent years (e.g., Gauthier et al., 1988; Norell \& Novacek, 1992; Benton \& Storrs, 1994; Huelsenbeck, 1994; Siddall, 1998; Wills, 1999; Benton et al., 2000, Angielczyk, 2002), the theoretical background of this relationship is just being explored (see Wagner, 2000, and Wagner \& Sidor, 2000).

The use of cladograms as temporal templates requires that: (i) the phylogenetic hypotheses depicted by cladograms are correct; (ii) all taxa acquire their diagnostic morphology at a similar rate; (iii) preservation and sampling do not alter directionally the correlation between the phylogenetic hierarchy and the order of appearance in the fossil record; and (iv) taxa with equal patristic distances from the base of the tree supposedly originated at the same time.

\section{PHYLOGENETIC BIOCHRONOLOGY}

\section{Aims}

The method presented here ordinates fossil assemblages (also termed "faunas") according to the phylogenetic signals of their faunal components. The result is termed 'phylogenetic biochronology'. The protocol concerns a set of faunas known to occur within a given time interval, and it focuses on the ordination of these faunas within that interval. It objectively and explicitly assigns each assemblage an evolutionary score that is used as a temporal index for the ordination.

\section{Data}

Faunal lists of well-known assemblages from a selected time interval are compiled. In order to avoid circular arguments, the upper and lower limits of the interval must be chosen conservatively to make sure that all the faunas to be analysed actually belong to that time span. Major clades with common occurrence across those faunas and with well-documented phylogenies are then selected. These clades must contain only taxa occurring above the lower limit of the interval, below which the clades must already be individualized. We advocate the use of faunas that have representatives of at least two of the selected clades (see below). In addition, the cladograms should contain terminal taxa that are as little inclusive as possible.

Here a constructed dataset of ten fossil assemblages is used to illustrate the method. These assemblages share very few taxa and cannot be ordinated using stratigraphic or radiometric data (Figure 2). Their faunal components belong to 3 major clades $(\alpha, \beta$, and $\gamma)$ that are known to survive the chosen time interval and that will be used for the ordination.

\section{Protocol}

Each terminal taxon of clades $\alpha, \beta$, and $\gamma$ is assigned a score ("S") equal to the number of nodes between it and the root of the cladogram (Figure 3A). Each cladogram has a maximum score (" $\mathrm{S}_{\max }$ ") equal to the value of the most derived member of this clade recorded in at least one of the studied faunas.

Different clades do not necessarily have the same number of splitting events in a given time interval. Therefore, the score $\mathrm{S}$ of each terminal taxon is normalized relative to the $\mathrm{S}_{\max }$ of the cladogram to which it belongs. This normalized value, termed the "branching index , equals $(\mathrm{S}-1) /\left(\mathrm{S}_{\max }-1\right)$. Thus, the most basal taxon will have a branching index of 0 , while the most derived will have a branching index of 1 . For example, in the case of Figure 3, taxon D has a score of 3 in a cladogram with a $S_{\max }$ of 5 (clade $\alpha$ ). The branching index of taxon $\mathrm{D}$ is thus $(3-1) /(5-1)=0.5$.

Within a single assemblage, only the branching index of the most derived taxon of each clade is used in the analysis (Figure 3B). Indeed, we believe that these taxa are the bearers of the most informative phylogenetic signal for biochronological purposes, because they represent the minimum 'level of evolution' sampled from a fauna. One may suggest that this approach disregards potentially useful information from other faunal components. However, under the assumptions previously discussed, the occurrence of primitive forms together with derived ones illustrates their survival from earlier time units.

Finally, each assemblage is characterized by the highest branching indices of its constituent clades (Figure 3B). The higher the indices, the younger the fauna is expected to be. If all the clades used in the analysis tend to yield similar signals, one should expect to find a positive correlation among the ordinations of the branching indices provided by each of them. If all the clades are represented in all the assemblages, a Kendall coefficient of concordance W (corrected for ties and with $a$ set at 5\%) can be computed and tested for significance. However, because assemblages will often lack representatives of one or more clades, the order correlation is tested using a Spearman rank-order correlation metric (onetailed, corrected for ties, and with $\alpha$ set at 5\%). This measure of correlation is computed for the branching indices yielded by each pair of clades (Figure 3C). Clearly, the test concerns only the subset of assemblages containing representatives of both clades. This is one of the reasons why the assemblages selected for the analysis should contain 


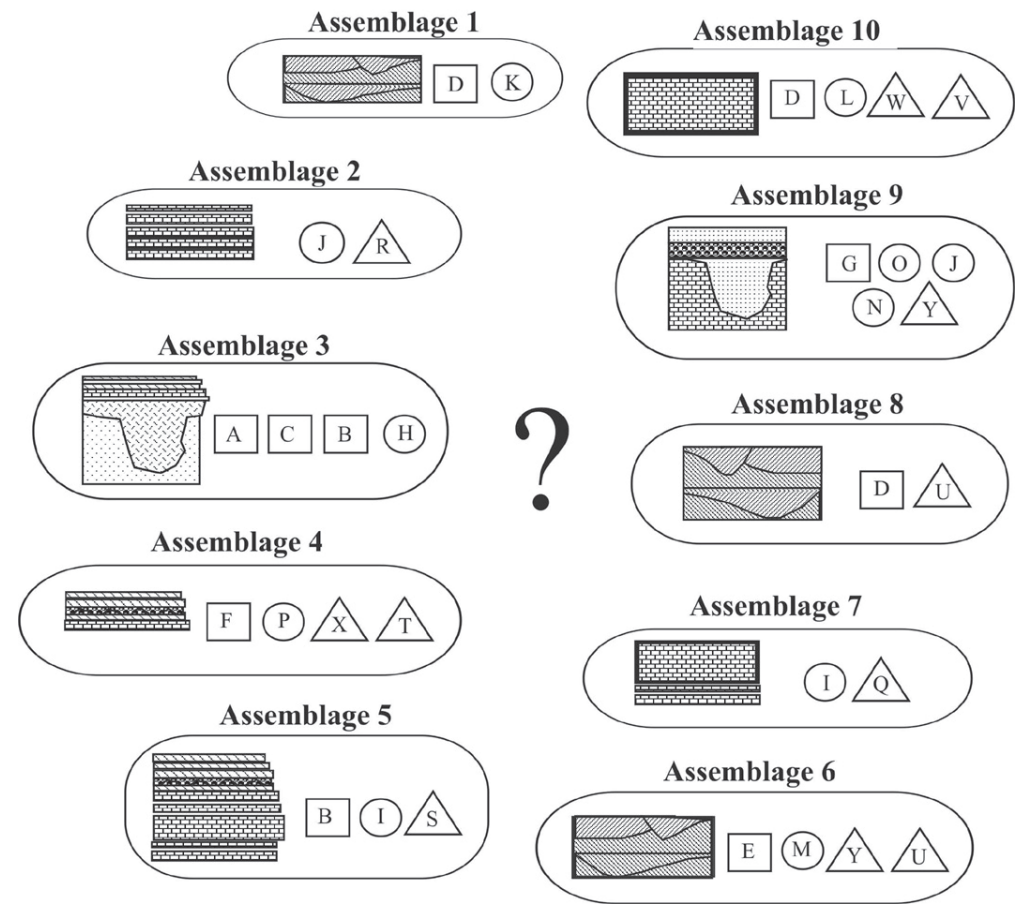

Figure 2. Ten fossil assemblages are known to contain representatives of clade $\alpha$ (letters $A$ to $G$ in square symbols), clade $\beta$ (letters $H$ to $O$ in circles), and clade $\gamma$ (letters $P$ to $Y$ in triangles). Very few taxa are shared among these assemblages, preventing the application of most biostratigraphic correlation and ordination methods. In the absence of any other temporal evidence (stratigraphic superposition, radiometric data), the phylogenetic status of the faunal components may help to ordinate these assemblages.
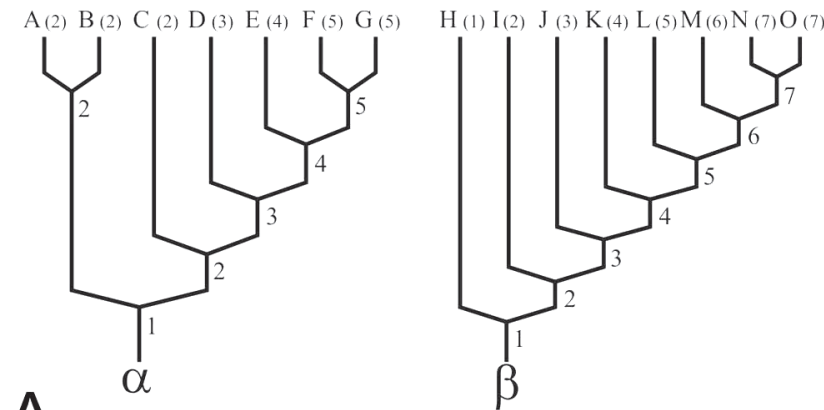

\begin{tabular}{|c|c|c|c|c|c|c|c|c|}
\hline & & \multicolumn{2}{|c|}{$\alpha$} & \multicolumn{2}{|c|}{$\beta$} & \multicolumn{2}{|r|}{$\gamma$} & \multirow{2}{*}{$\begin{array}{l}\text { Evolutionary } \\
\text { Indices (E. I.) }\end{array}$} \\
\hline & & Taxa & B. I. & Taxa & B.I. & Taxa & B. I. & \\
\hline Assemblage & 1 & $\mathrm{D}$ & 0.50 & $\mathrm{~K}$ & 0.50 & - & - & 0.50 \\
\hline Assemblage & 2 & - & - & $J$ & 0.33 & $R$ & 0.20 & 0.26 \\
\hline Assemblage & 3 & A & 0.25 & $\mathrm{H}$ & 0.00 & - & - & 0.12 \\
\hline Assemblage & 4 & $\mathrm{~F}$ & 1.00 & $\mathrm{P}$ & 0.40 & X & 1.00 & 0.81 \\
\hline Assemblage & 5 & B & 0.25 & I & 0.17 & S & 0.20 & 0.20 \\
\hline Assemblage & 6 & E & 0.75 & M & 0.83 & Y & 1.00 & 0.88 \\
\hline Assemblage & 7 & - & - & I & 0.17 & Q & 0.40 & 0.30 \\
\hline Assemblage & 8 & D & 0.50 & - & - & $\mathrm{U}$ & 0.80 & 0.68 \\
\hline Assemblage & 9 & G & 1.00 & O & 1.00 & Y & 1.00 & 1.00 \\
\hline Assemblage & 10 & D & 0.50 & $\mathrm{~L}$ & 0.67 & W & 0.80 & 0.67 \\
\hline
\end{tabular}

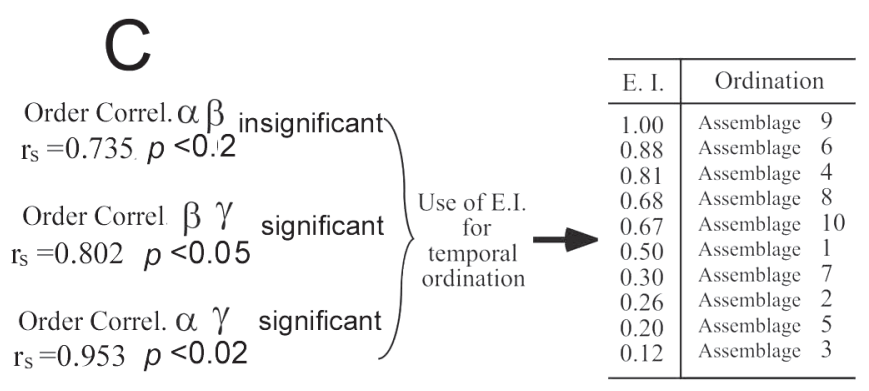

Figure 3. Protocol for erecting a phylogenetic biochronology applied to the assemblage 1 to 10 as described in Figure 2. The ordination is based on information from the three clades $\alpha, \beta$, and $\gamma$. First, the nodes of each cladogram are numbered according to the number of nodes passed from the root, and each terminal taxon is assigned a score equal to the number of the last node supporting its branch (A). Second, the branching index (B. I.), i.e. the ratio of a taxon's score minus 1 to the maximum score possible in its cladogram minus 1 , is calculated for each terminal taxon. For each assemblage, the representatives of the various clades with the highest branching index are retained for the analysis (B). The average of these highest branching indices, weighted for clade size, corresponds to the evolutionary index (E. I.). The rank correlation of the branching indices is assessed by a Spearman rank-order correlation test for each pair of clades. As a majority of the rank correlations are significant, the evolutionary indices can be used for the temporal ordination of the fossil assemblages (C). 
representatives of at least two clades. If the majority of the order correlation tests are not significant, no clear phylogenetic signal arises from the faunal components and the ordination of the assemblages on this basis is compromised. This is because the Spearman analysis tests a null hypothesis of no association among phylogenetic ranks across the clades in an assemblage. If a majority of the clades yield orders that are significantly correlated (as in the example of Figure 3C), the overall phylogenetic signal can be more confidently used for the temporal ordination of the assemblages. Note that even if two clades yield ordinations close to each other, tied observations, missing data, and sample size (number of assemblages) affect the level of significance of the test. The simplest way to summarize the correlation signal from the different clades is to average the branching indices (weighted for the clade size) into an "evolutionary index", unique to each assemblage (Figure 3B). Clearly, the evolutionary index is more sound when the clades yield more similar signals (i.e. the order correlations are significant for most of the clade pairs). As the temporal information is summarized by the evolutionary indices, the latter are used to ordinate the assemblages (Figure 3C).

\section{The Problem of Extinction}

In the example discussed above, only clades known to have survived the time-interval of interest were considered. However, other clades that were present in this interval, but became extinct before its upper limit, are also important. Indeed, these extinct clades are potentially informative for the erection of a phylogenetic biochronology and should be used in the analysis. To include them at first hand would be misleading though, because their absence in the fossil record could be due to either spurious missing data or the result of their extinction.

Figure 4 shows the theoretical case of two clades, $\delta$ and $\varepsilon$, considered in the study of two assemblages with a known temporal position (Assemblages 1 and 2). Clade $\delta$ is known to survive the time interval, whereas clade $\varepsilon$ becomes extinct (white arrow). In this example, the evolutionary index of the older assemblage (Assemblage 1) is based on signals from both clades $\delta$ and $\varepsilon$, and the presence of a highly derived member of the clade $\varepsilon$ results in a high evolutionary index. On the other hand, the extinction of the clade $\varepsilon$ affects the evolutionary index of the younger assemblage (Assemblage 2 ), which is pushed down due to the absence of derived members of that clade. In this case, the two faunas would be placed in the wrong temporal order.

To avoid this bias, a first analysis is run only with clades that are known to survive through the entire interval. Based on the order obtained from this first analysis, the fauna with the last representatives of the most recently extinct clade defines the upper boundary of a sub-set of faunas (Figure 5).

A second analysis is then run with this new data-set,

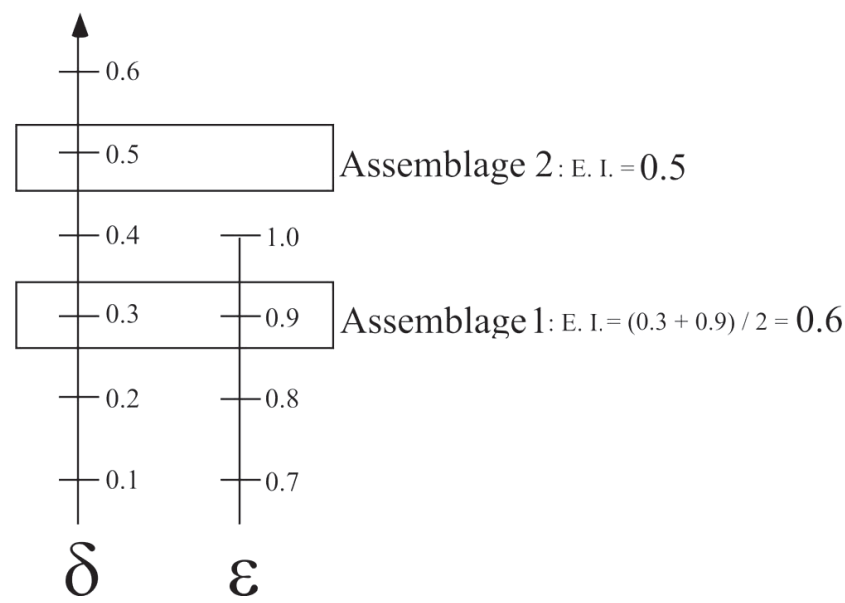

Figure 4. The problem of extinction. The clades $\delta$ and $\varepsilon$ are represented by their respective succession of branching indices. For simplicity, the corresponding cladograms are supposed to have the same size. Clade $\delta$ is known to survive the time interval under consideration, whereas clade $\varepsilon$ becomes extinct (white arrow). The simultaneous use of these two clades to calculate the evolutionary indices of Assemblage 1 and 2 leads to the placement of the latter in the wrong temporal order.

including the signal of the youngest extinct clade. This procedure is repeated until all successive extinct clades are considered, with the information from the subsequent analyses replacing the order provided by the previous ones (Figure 5). Note, however, that a different scorenormalization must be applied for each subsequent analysis, i.e. the branching indices are calculated relative to the maximum score of each clade found within each subset of faunas.

The faunas that were not incorporated into the subsets used in the successive analyses are kept in their original sequence. Their superposition produces the final order of faunas (Figure 5). This order has been entirely established according to the hierarchy of phylogeny estimates, and it corresponds to what is termed here a phylogenetic biochronology. Other sources of evidence can subsequently be used to calibrate the phylogenetic biochronology on an absolute timescale and for discussing its outcomes.

\section{DISCUSSION}

\section{Cladograms and phylogenies}

Ideally, a phylogenetic biochronology should rely on the historical relationships between ancestors and descendents. Here, however, the temporal information is drawn from cladograms. The use of cladograms as a primary source for temporal ordination thus raises the issue of ancestry. Taxa diagnosed by plesiomorphic characters are common among fossil taxa, and these potential ancestral forms are likely to be found in the fossil record (Foote, 1996).

Therefore, a cladogram can contain taxa that might be direct ancestors to other taxa (Eldredge, 1979; Smith, 1994), illustrating an anagenetic or a budding speciation pattern 
First analysis

(S.C. only) Second analysis

$($ S.C. $+\varepsilon)$
Third analysis

$($ S.C. $+\varepsilon+\zeta)$

\section{Fourth analysis}

$$
(\text { S.C. }+\varepsilon+\zeta+\eta) \quad \text { Final Order }
$$

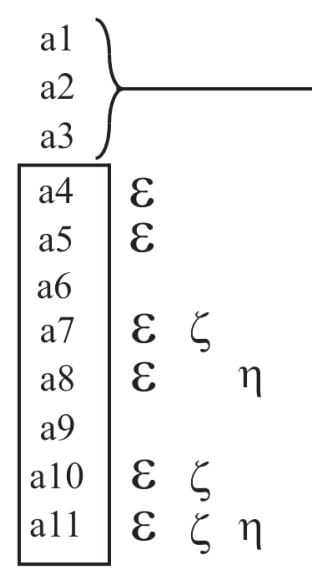

Ass embl. Extinct clades

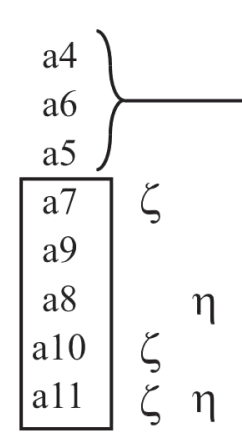

Ass embl. Extinct

Clades

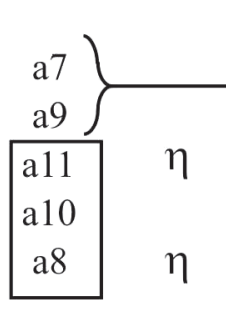

Assemb1. Extinct clade al

a4

a6

a5

a7

a9

a10

a11

a8

Ass embl.

Figure 5. Theoretical example showing the successive analyses necessary when clades becoming extinct during the studied time interval are considered. The first analysis includes the surviving clades (S.C.) only, and the occurrences of the extinct clades $(\varepsilon$, $\zeta$ and $\eta)$ are plotted against the resulting order of the assemblages a1 - a11. The subsequent analyses successively integrate the most recently extinct clade in the computations. The subset of assemblages that are not used in each subsequent analysis composes the final order (see text).

instead of bifurcating one. Metaspecies (Donoghue, 1985) are candidate for the status of ancestor. If such taxa are recognised in the cladograms used for phylogenetic biochronology, they should simply be scored one unit less than their apomorphybearer sister taxon. For example, in a hard trichotomy (A*, B, C), the metataxon $\mathrm{A}^{*}$ will be scored $n$ whereas taxa $\mathrm{B}$ and $\mathrm{C}$ will be scored $n+1$ for the analysis. Also, successive representatives of an anagenetic lineage (e.g. A*-B*-C*-D) are data for which the algorithm would work best because they represent a strict temporal sequence for which there is no range overlap. The use of lineages as temporal indicators is also the basis of Martinez's (1995) cladochronological analysis, although this method applies a parsimony criterion to the data and it relies on derived taxa shared by severeal assemblages (see Marivaux, 1999 for a discussion).

Phylogenetic biochronology is particularly useful for poorly-correlated assemblages that share few taxa or none, but it also requires robust phylogenetic reconstructions. However, it seems that phylogenetic reconstructions become less accurate as sampling decreases (Wagner, 2000). Therefore, the method will be more reliable when the phylogenetic relationships used in the analysis are inferred from a larger pool of evidence than the one offered by the single-occurrence assemblages to be ordinated. For clades with poorly resolved phylogenies, phylogenetic-free biostratigraphic methods are therefore recommended.

\section{Tree Balance and Clade Size}

Figure 6 shows the two extreme topologies of cladogram symmetry: a perfectly imbalanced ("pectinate") cladogram, and a fully balanced one. Note that both clades have the same size. Terminal taxa from the imbalanced cladogram (Figure 6A) all have different branching indices (with the exception of the least inclusive subclade), and therefore the pectinate topology provides a maximum level of resolution for the ordination. Conversely, terminal taxa from the fully balanced cladogram (Figure 6B) all have the same branching index, which is inevitably the highest one. Under the assumptions of the method, all these taxa originated at the same time, so that no ordination is possible. Accordingly, imbalanced cladograms with numerous terminal taxa seem more favorable to the erection of phylogenetic biochronologies. How do these theoretical requirements fit with empirical observations?

It has been shown that paleontological trees are generally more imbalanced than neontological trees, certainly because they are time-transgessive (Harcourt-Brown et al., 2001). This emphasizes the intimate relationship between topological patterns and the underlying macroevolutionary processes (e.g. Mooers \& Heard, 1997). Indeed, the survival and later speciation of a taxon will lead to asymmetry if its sister taxon becomes extinct, and imbalanced topology is promoted when extinction affects more basal taxa. Pearson (1998b) suggested that the asymmetry observed in empirical stratophenetic trees arises from the higher extinction rate (and lower speciation rate) of plesiomorphic species compared to their daughter species. These are encouraging observations because the earlier extinction of "basal" taxa improves the informativeness of more derived taxa in terms of temporal sequence.

In addition to the balance of cladograms, the size of the 

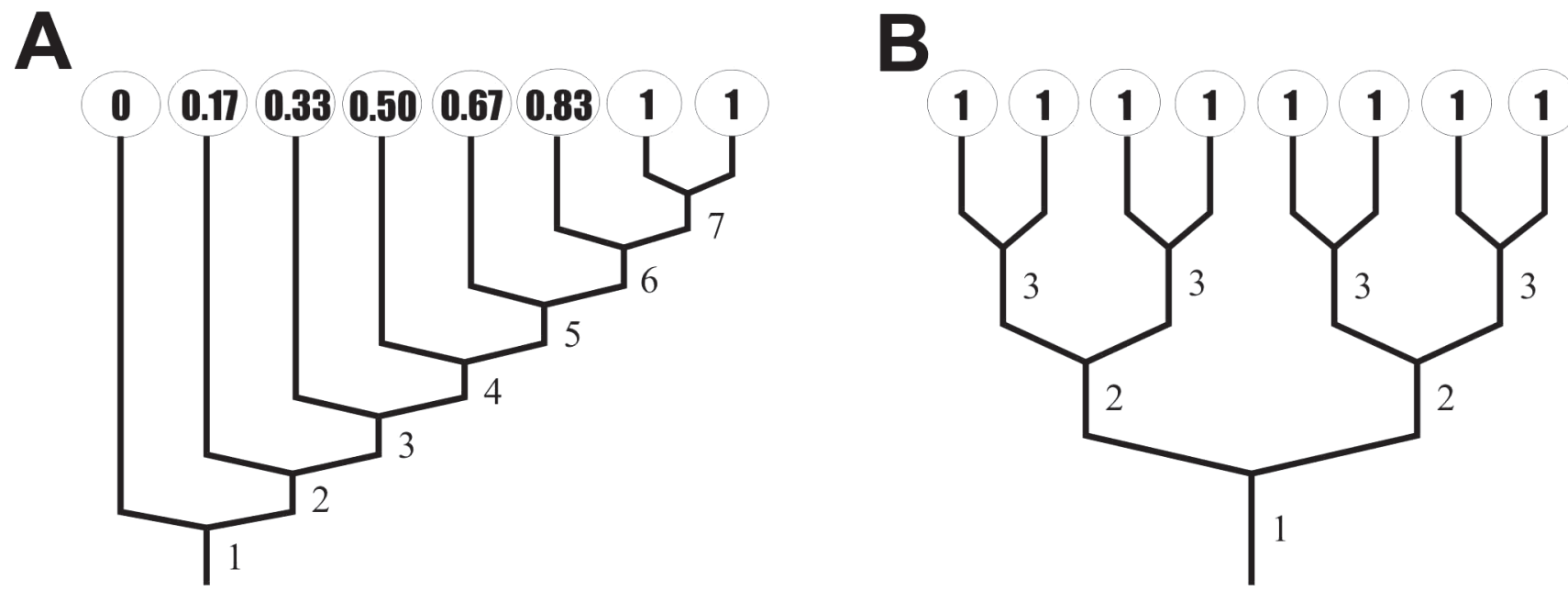

Figure 6. The effect of tree balance. An imbalanced cladogram (A) yields more varied branching indices than does a balanced cladogram (B). The former case is thus preferable for ordination.

clades (i.e., the number of terminal taxa) also has an influence on the method. Figure 7 shows two imbalanced cladograms with 3 and 11 terminal taxa respectively. Case A yields only two values for the branching indices ( 0 and 1$)$, whereas Case $\mathrm{B}$ yields 10 branching indices ranging from 0 to 1 . In general, small clades will give few values for branching indices. Big clades are preferable in that they provide a wider range of branching indices that increases the resolution of the ordination. Note that clade size is discussed in the case of imbalanced cladograms because this parameter does not affect the branching indices of fully balanced cladograms.

\section{Robustness of the ordination}

The theoretical premises necessary for using cladograms as temporal templates (see third section) are undoubtedly violated on many instances. Clearly, not all taxa acquired their diagnostic morphology at a similar rate, and not all taxa with equal patristic distances from the base of the tree originated at exactly the same time. A plethora of other factors can explain why the fit between stratigraphic and cladistic data is never perfect (e.g., Gauthier et al., 1988, Norell \& Novacek, 1992). In order to be useful, the method introduced here expects that an overall congruence occurs
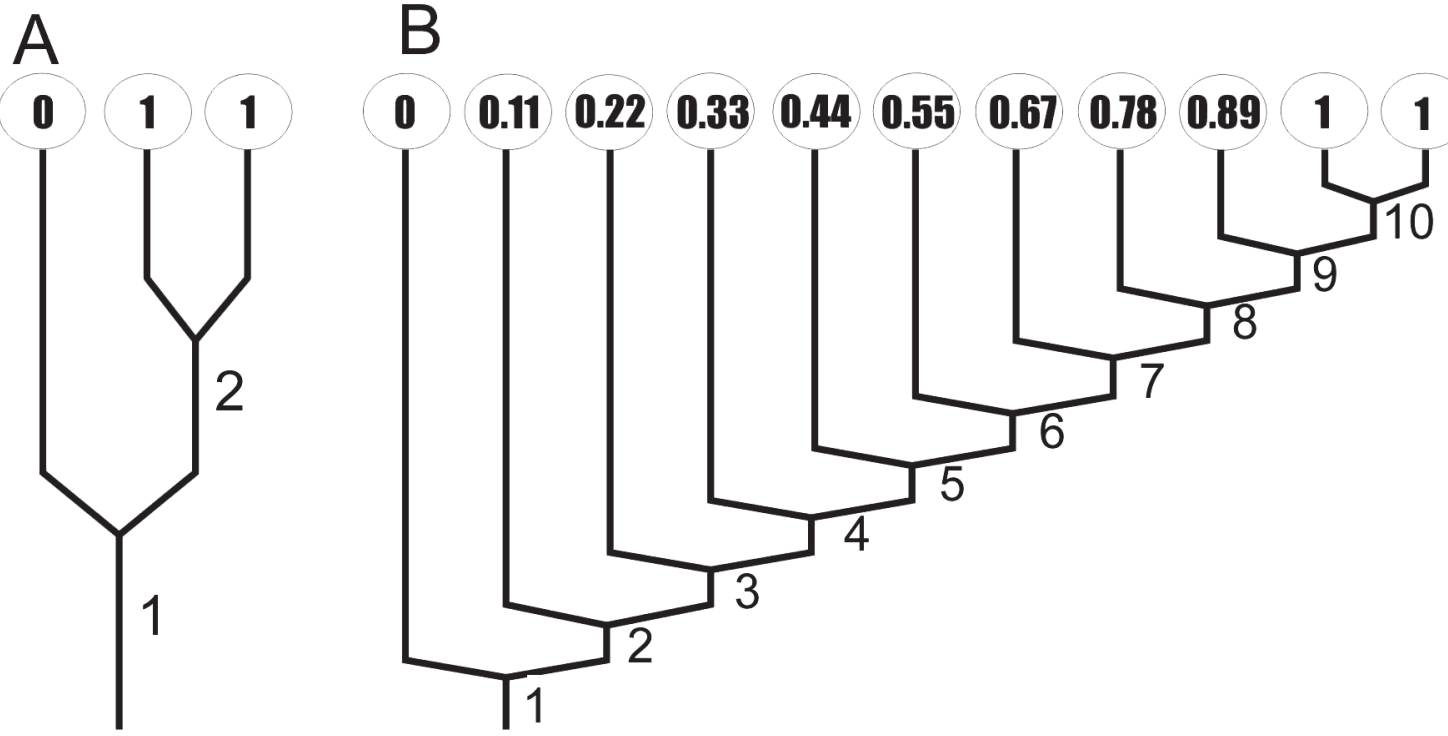

Figure 7. The effect of clade size. A small clade (A) tends to yield few branching indices, whereas a bigger clade (B) provides a wider range of branching indices, increasing the resolution for the ordination. 
in most cases. Is this observed empirically? Various indices of congruence have been employed in large-scale empirical studies (see Benton et al., 1999 for a discussion), especially the Relative Completeness Index (RCI; Benton \& Storrs, 1994), the Stratigraphic Consistency Index (SCI; Huelsenbeck, 1994), and the Gap Excess Ratio (GER; Wills, 1999). Only the two latter are relevant here because they depend only on the estimated dates of origin of groups. In a large overview of 376 cladograms of echinoderms, fishes and tetrapods, Benton \& Hitchin (1996) found that SCI values were greater than, or equal to, 0.50 in $79 \%$ of cases. That means that a majority of the tested cladograms have more than half their nodes showing stratigraphic consistency than inconsistency. A similar study based on a larger sample of 1000 published cladograms (covering nearly all taxonomic groups) yielded an SCI mean value of 0.551 and a GER mean value of 0.562 (Benton et al., 2000). This result suggests an overall congruence between stratigraphic and phylogenetic data, although the match is far from being perfect.

In addition, the proportion of index values significantly better or worse than those expected from a random distribution was found to be very unevenly distributed among taxonomic groups (Benton et al., 1999). Phylogenetic biochronology is therefore subject to error, but we feel that the algorithm is worthwhile for two reasons.

First because it seems improbable that potential biasing factors affect all clades in a similar manner. Comparison of the ordinations provided by the different clades using Spearman rank-order correlation coefficients is therefore a key test of the overall phylogenetic signal emerging from the data. A global agreement attests a strong signal, which itself is believed to represent a temporal pattern. Note that one can delete a clade a posteriori if it is systematically in contradiction with the signal from all the others, or if it is too poorly represented in the analyzed assemblages. Clearly, the more clades that are considered in the analyses, the more robust the final order of faunas is expected to be. It seems unlikely that the assumption of global congruence between the fossil record and phylogenies would be violated for all the groups at the same time, making all clades uniformly point towards an incorrect temporal pattern. The robustness of the method can also be assessed by comparing the resulting final order with that obtained when the second most derived taxa are used in the calculations. The consistency among the orders would also support the strength of the phylogenetic signal.

Second, the algorithm is a heuristic approach that can reveal important mismatches between the fossil record, phylogenetic hypotheses, and evolutionary models. Phylogenetic biochronology can be tested with a post hoc confrontation with other evidence, such as stratigraphic superposition and radiometric data. At present, the method does not integrate such evidence in the computations and it is therefore similar to the biochronological approach of Martinez (1995) in this respect. Because stratigraphy is an irreplaceable source of temporal information, the future of phylogenetic biochronology will certainly need the integration of this parameter in the algorithm. Also, it is important to stress that the method should not be applied if there has been some use of biochronological data in the estimation of phylogeny. This assumption is also central to Martinez's (1995) method and its violation would lead to circular reasoning.

The mean temporal spacing of nodes is also critical for the congruence between phylogenetic and stratigraphic data: the longer the stratigraphic span of the members of a clade, the better the congruence (Norell \& Novacek, 1992; Benton et al., 1999). Therefore, phylogenetic biochronology is less reliable for samples closely spaced in time, and we do not recommend it for studies made within short time intervals.

\section{CONCLUSIONS}

We have argued here that phylogeny estimates may provide, in some instances, an independent framework to ordinate fossil assemblages. Although the theoretical requirements may be violated on some occasions, phylogenetic biochronologies provide heuristic results that should complete the traditional biostratigraphic inferences.

Phylogenetic biochronology could be particularly useful in two situations. First, and in contrast to most other quantitative methods, it allows the ordination of distant assemblages that have few or none co-occurring taxa. In turn, it may be useful for studying some parts of the vertebrate fossil record. Second, phylogenetically-based ordination can propose a succession of faunas when there is no straightforward stratigraphic control of their superposition (for example in a complex tectonically disrupted region).

As for all other quantitative biostratigraphic approaches, the outcome of the method is a dynamic hypothesis because additional evidence will constantly update the results. In fact, new finds can either keep a fauna at the same position in the relative order (newly-found taxa are less or equally derived to those previously known), or make the fauna rise to a younger position (newly-found taxa are more derived than those previously known). New finds may also modify the results by changing the inferred phylogenetic structure of a clade. In such a case, however, the impact on the results is more difficult to predict.

Phylogenetic information brings additional - but nonexclusive - arguments for the relative placement of faunas through time. The method presented here can be viewd as an exploratory tool and inconsistencies among different sources of chronological information could indicate that the temporal signal given by evolutionary indices is misleading. The potential mismatches point towards interesting aspects of paleoecology, paleobiogeography, quality of the fossil record, and accuracy of phylogenetic hypotheses. Although the main theoretical assumptions and limitations of the method 
are presented here, much work remains to be done on both theoretical and empirical grounds. The use of phylogeny estimates for biochronological inferences is still in its infancy, and the present contribution is a first step that will hopefully stimulate further investigations in this field.

\section{ACKNOWLEDGEMENTS}

We wish to thank C.A. Sidor, P.N. Pearson, J. Alroy, P.J. Wagner and T. Olszewski and two anonymous reviewers for their constructive comments of early drafts of the manuscript. Although they do not always agree with some of our ideas, their reviews greatly improved this paper. For financial support, EF acknowledges a University of Bristol Postgraduate Scholarship (U.K.) and a CNRS Post-doctoral fellowship (France), and MCL is indebted to the Committee of Vice-Chancellors and Principals of the Universities of the United Kingdom.

\section{REFERENCES}

Alroy, J. 1992. Conjunction among taxonomic distributions and the Miocene mammalian biochronology of the Great Plains. Paleobiology, 18(3):326-343.

Alroy, J. 1994. Appearance event ordination: a new biochronological method. Paleobiology, 20(2):191-207.

Angielczyk, K.D. 2002. A character-based method for measuring the fit of a cladogram to the fossil record. Systematic Biology, 51(1):176-191.

Benton, M.J. \& Hitchin, R. 1996. Testing the quality of the fossil record by groups and by major habitats. Historical Biology, 12:111-157.

Benton, M.J. \& Storrs, G.W. 1994. Testing the quality of the fossil record: paleontological knowledge is improving. Geology, 22:111-114.

Benton, M.J.; Hitchin, R. \& Wills, M.A. 1999. Assessing congruence between cladistic and stratigraphic data. Systematic Biology, 48(3):581-596.

Benton, M.J.; Wills, M.A. \& Hitchin, R. 2000. The quality of the fossil record through time. Nature, 403:534-537.

Burroughs, W.A. \& Brower, J.C. 1982. SER, a Fortran program for the seriation of biostratigraphic data. Computers and Geosciences, 8:137-148.

Donoghue, M.J. 1985. A critique of the biological species concept and recommendations for a phylogenetic alternative. Bryologist, 88:172-181.

Eldredge, N. 1979. Cladism and common sense. In: J. Cracraft \& N. Eldredge (eds.) Phylogenetic analysis and paleontology, New York, Columbia University Press, p. 165-198.

Fisher, D.C. 1992. Stratigraphic parsimony. In: W.P. Maddison \& D.R. Maddison (eds.) MacClade: analysis of phylogeny and character evolution, Version 3, Sunderland, Massachussetts, Sinauer Associates, p. 124-129.

Fisher, D.C. 1994. Stratocladistics: morphological and temporal patterns and their relation to phylogenetic process. In: L. Grande \& O. Rieppel (eds.) Interpreting the hierarchy of nature, San Diego, Academic Press, p. 133-171.

Foote, M. 1996. On the probability of ancestors in the fossil record.
Paleobiology, 22(2):141-151.

Gauthier, J.; Kluge, A. \& Rowe, T. 1988. Amniote phylogeny and the importance of fossils. Cladistics, 4:105-209.

Gerrienne, P. \& Streel, M. 1994. A biostratigraphic method based on a quantification of the characters of Devonian tracheophytes. Paleobiology, 20:208-214.

Gingerich, P.D. 1979. The stratophenetic approach to phylogeny reconstruction in vertebrate paleontology. In: J. Cracraft \& N. Eldredge (eds.) Phylogenetic analysis and paleontology, New York, Columbia University Press, p. 41-77.

Guex, J. 1977. Une nouvelle méthode d'analyse biochronologique. Bulletin du Laboratoire de Géologie Université de Lausanne, 224:309-322.

Guex, J. 1987. Corrélations biochronologiques et associations unitaires. Bern, Presses Polytechnique Romandes, 244 p.

Guex, J. 1991. Biochronological correlations. Berlin, SpringerVerlag, 250p.

Harcourt-Brown, K.G., Pearson, P.N. \& Wilkinson, M. 2001. The imbalance of paleontological trees. Paleobiology, 27:188-204.

Heckert, A.B. \& Lucas, S.G. 1998. First use of ornithischian dinosaurs for biostratigraphic zonation of the Upper Triassic. Albertiana, 20:58-63.

Heckert, A.B. \& Lucas, S.G. 2002. South Amercian occurrences of the Adamanian (Late Triassic: latest Carnian) index taxon Stagonolepis (Archosauria: Aetosauria) and their biochronological significance. Journal of Paleontology, 76(5):852-863.

Hedberg, H.D. 1976. International stratigraphic guide. A guide to stratigraphic classification, terminology, and procedure. New York, Wiley \& Sons, 200 p.

Hennig, W. 1966. Phylogenetic Systematics. Urbana, University of Illinois Press, 263 p.

Hooker, J.J. 1996. Mammalian biostratigraphy across the PaleoceneEocene boundary in the Paris, London, and Belgian Basins. In: R.W.O.B. Knox, R.M. Corfield \& R.E. Dunay (eds.) Correlation of the early Paleogene in Northwest Europe, London, Geological Society Special Publication 101, p. 205-218.

Huelsenbeck, J.P. 1994. Comparing the stratigraphic record to estimates of phylogeny. Paleobiology, 20(4):470-483.

Lucas, S.G. \& Hunt, A.P. 1993. Tetrapod biochronology of the Chinle Group (Upper Triassic), Western United States. In: S.G. Lucas \& M. Morales (eds.) The nonmarine Triassic, New Mexico Museum Natural History \& Science Bulletin, v. 3, p.327-329.

Marivaux, L. 1999. Application de méthodes de biochronologie quantitative aux faunes de mammifères du Paléogène continental d'Europe occidentale. Bulletin de la Societé géologique de France, 170(3):335-347.

Martinez, J.N. 1995. Biochronologie et méthode de parcimonie. Bulletin de la Societé géologique de France, 166(5):517-526.

Mooers, A.Ø. \& Heard, S.B. 1997. Inferring evolutionary processes from phylogenetic tree shape. Quarterly Review of Biology, 72:31-54.

Norell, M.A. \& Novacek, M.J. 1992. The fossil record and evolution: comparing cladistic and paleontologic evidence for vertebrate history. Science, 255:1690-1693.

Pearson, P.N. 1998a. Evolutionary concepts in biostratigraphy. In: P. Doyle \& M.R. Bennett (eds.) Unlocking the stratigraphical record: advances in modern stratigraphy. New York, Wiley \& Sons, p. 123-144.

Pearson, P.N. 1998b. Speciation and extinction asymmetries in paleontological phylogenies: evidence for evolutionary progress? 
Paleobiology, 24:305-335.

Rudwick, M.J.S. 1976. The meaning of fossils; episodes in the history of palaeontology. $2^{\mathrm{a}}$ ed. New York, Science History Publications, 287 p.

Siddall, M.E. 1998. Stratigraphic fit to phylogenies: a proposed solution. Cladistics, 14:201-208.

Simpson, G.G. 1944. Tempo and mode in evolution. New York, Columbia University Press, 237 p.

Simpson, G.G. 1953. The major features of evolution. New York, Columbia University Press, 437 p.

Smith, A.B. 1994. Systematics and the fossil record, documenting evolutionary patterns. Oxford, Blackwell Science, 223 p.
Wagner, P.J. 2000. The quality of the fossil record and the accuracy of phylogenetic inferences about sampling and diversity. Systematic Biology, 49(1):65-86.

Wagner, P.J. \& Sidor, C.A. 2000. Age rank/clade rank metricssampling, taxonomy, and the meaning of "stratigraphic consistency". Systematic Biology, 49(3):463-479.

Wills, M.A. 1999. The congruence between phylogeny and stratigraphy: randomization tests and the Gap Excess Ratio. Systematic Biology, 48(3):559-580.

Received March, 2004; accepted April, 2004. 